\title{
Staff perceptions of a Productive Community Services implementation: A qualitative interview study
}

\author{
Dominique Kim Frances Bradley*, Dr. Murray Griffin \\ University of Essex, Wivenhoe Park, Colchester, Essex, United Kingdom
}

\section{A R T I C L E I N F O}

\section{Article history:}

Received 3 September 2014

Received in revised form 4 February 2015

Accepted 6 February 2015

\section{Keywords:}

Productive Community Services

Releasing Time to Care

Thematic analysis

Innovation

\begin{abstract}
A B S T R A C T
Background: The Productive Series is a collection of change programmes designed by the English National Health Service (NHS) Institute for Innovation and Improvement to help frontline healthcare staff improve quality and reduce wasted time, so that this time can be reinvested into time spent with patients. The programmes have been implemented in at least 14 countries around the world. This study examines an implementation of the Productive Community Services programme that took place in a Community healthcare organisation in England from July 2010 to March 2012.

Objectives: To explore staff members' perceptions of a Productive Community Services implementation.

Design: Cross-sectional interview.

Settings: Community Healthcare Organisation in East Anglia, England.

Participants: 45 participants were recruited using purposive, snowballing and opportunistic sampling methods to represent five main types of staff group in the organisation; clinical team members, administrative team members, service managers/team leaders, senior managers and software support staff. Team members were recruited on the basis that they had submitted data for at least one Productive Community Services module. Methods: Semi-structured individual and group interviews were carried out after the programme concluded and analysed using thematic analysis.

Results: This report focuses on six of the themes identified. The analysis found that communication was not always effective, and there was a lack of awareness, knowledge and understanding of the programme. Many staff did not find the Productive Community Services work relevant, and although certain improvements were sustained, suboptimal practices crept back. Although negative outcomes were reported, such as the programme taking time away from patients initially, many benefits were described including improved stock control and work environments, and better use of the Electronic Patient Record system.

Conclusions: One of the themes identified highlighted the positive perceptions of the programme, however a focus on five other themes indicate that important aspects of the implementation could have been improved. The innovation and implementation literature already addresses the issues identified, which suggests a gap between theory and practice for implementation teams. A lack of perceived relevance also suggests that similar
\end{abstract}

\footnotetext{
* Corresponding author.

E-mail addresses: dkfwil@essex.ac.uk (D.K.F. Bradley), mgriffin@essex.ac.uk (M. Griffin).
} 
programmes need to be made more easily adaptable for the varied specialisms found in Community Services. Further research on Productive Community Services implementations and knowledge transfer is required, and publication of studies focusing on the less positive aspects of implementations may accelerate this process.

(c) 2015 Published by Elsevier Ltd.

\section{What is already known about the topic?}

There is little published research on the Productive Community Services programme, however the Productive Ward programme has been reported to have generated many benefits including increased patient contact time, increased quality and reduced inefficiencies.

- Much of the literature is positively biased, often using participants heavily involved in the programme.

- Relevant knowledge has not always been transferred to implementations of Productive Ward.

\section{What this paper adds}

- This paper examines an implementation of the Productive Community Services programme.

- The findings indicate that issues in communication, awareness and knowledge of the programme, relevancy and sustainability demonstrates that knowledge transfer for Productive Community Services implementation teams needs to be improved.

- The findings suggest that programmes like Productive Community Services need to be more easily adaptable for the various specialisms that exist in Community Services healthcare organisations.

\section{Introduction}

The Productive Series is a collection of change programmes designed by the English National Health Service Institute for Innovation and Improvement. Until March 2013 this organisation was established, “. . . to support the transformation of the NHS (National Health Service), through innovation, improvement, and the adoption of best practice," (NHS Institute for Innovation and Improvement, 2014). Since April 2014, a new organisation, NHS Improving Quality, has continued much of their work, including the administration of the Productive Series (NHS Institute for Innovation and Improvement, 2014). In 2007, the Productive Ward, the first of the Productive Series programmes was launched in England (Wright and McSherry, 2013), and the series now caters for various healthcare settings, including the Operating Theatre, General Practice and Community Services (see NHS Institute for Innovation and Improvement, 2011). They have been designed to improve quality and reduce wasted resources, in order for staff to be able to spend more time with patients (NHS Institute for Innovation and Improvement, 2012b); hence the programmes' secondary title, 'Releasing Time to Care ${ }^{\mathrm{TM}}$ '. This time spent with patients is often referred to as 'Patient-facing time' (York Health Economics Consortium and NHS Institute for Innovation and Improvement, 2010) or 'Direct care time' (Wright and McSherry, 2013). The programmes also aim to increase the capability of healthcare organisations so that staff are equipped to improve to their day-to-day processes themselves (Bevan, 2010).

Although White et al. (2013) identified a large amount of grey literature and reports regarding the Productive Ward programme, Wright and McSherry (2013) found only 18 articles that passed their quality and relevancy assessment published between 2005 to 2011, classing only five of these as empirical research. They identified a bias towards the publication of positive results, and indications of sustainability issues, where Productive Ward-related publications increased towards 2009 and then declined. They propose a 'Productive euphoria' was associated with this increase, which occurred because the programmes were seen to offer solutions to the problems regarding insufficient care that healthcare organisations were perceived to provide at that time. A similar rise and decline of grey literature and evaluations was identified by a bibliometric profile of Productive Ward literature published between 2006 and 2013, although the number of peer-reviewed articles remained steady but low (White et al., 2014).

Anecdotal and experiential articles (Wright and McSherry, 2013) mostly highlight the benefits generated by the programme. Harrison (2008) demonstrates how Productive Ward tools helped staff to identify issues that needed to be addressed (for example, scoring $0 \%$ on an observation audit) and gives examples of the steps they took to improve. Similarly, a Senior Associate at the NHS Institute for Innovation and Improvement, (Manning, 2011) promotes the Productive Community Services, referring to improvements such as a $48 \%$ reduction in stock held for a school nursing team. Productive Ward has also been associated with increased quality of patient observations and patient satisfaction (Lipley, 2009), increased staff satisfaction (Dean, 2014; Wright et al., 2012), increased Direct Care Time with patients (Blakemore, 2009), the reduction of hospital-acquired infections (Foster et al., 2009; Smith and Rudd, 2010) staff sickness (Smith and Rudd, 2010), and falls (Wilson, 2009), and more efficient admission and discharge processes (Lennard, 2014). Few of these articles provide much detail regarding the negative aspects of the programme's implementation, although for an exception see Wright et al. (2012), who notes that implementing just the first module cost $£ 236$ per meeting in staff time before accounting for the time taken to prepare data and carry out the module work.

The Productive Series has been distributed to at least 14 countries (NHS Scotland, 2013) including New Zealand (see Moore et al., 2013) and Canada (see Avis, 2012), 
although the available literature on these implementations are mostly internal experiential reports rather than peerreviewed empirical research. For example, NHS Scotland (2008) evaluated Productive Ward in eight Scottish NHS boards and reported benefits including increased direct care (ranging from 13 to $43 \%$ ), reduced unplanned staff absence (from $6.27 \%$ to $2.97 \%$ ), and increased efficiency, for example by reducing the number of steps required to carry out processes. However NHS East of England (2010) found that the great impact achieved by Productive Ward was difficult to quantify because measurable outcomes had not been defined. Communication 'from ward to the board,' (, p. 19) and organisational engagement were seen among others as crucial in maximising the programme's impact and sustainability. The National Nursing Research Unit and NHS Institute for Innovation and Improvement (2010b) also propose that, "... the single most important factor for the success of Productive Ward is that clinicians need to be supported and encouraged by the senior leaders in their organisations," (National Nursing Research Unit and NHS Institute for Innovation and Improvement, 2010b, p. 6). National Nursing Research Unit and NHS Institute for Innovation and Improvement (2010a) note that the clear communication of management support was likely to be more difficult in organisations with multiple sites than those on single sites.

Qualitative research by Davis and Adams (2012) was carried out using semi-structured interviews with six staff members in order to investigate their perceptions about Productive Ward. Using thematic analysis, they identified five main themes; "Starting to implement the programme, Anxiety and defensiveness, The Importance of leadership and communication, Challenges, and Learning and personal development," (, p. 354). Although their study captured some of the negative issues that were encountered during implementation, the responses were wholly positive, although only a small sample of staff were interviewed, and the participants were leading or heavily involved with the programme.

White and Waldron (2014) reviewed literature published between 2006-2013 to investigate the impact of Productive Ward. By using qualitative content analysis, focusing on nurses' perspective of the programme, they found that 'Empowerment', 'Leadership' and 'Engagement' were the top three most common impacts reported. However a literature review by White et al. (2013) focused more on the implementation process, which identified seven key characteristics that were seen to have a direct impact on Productive Ward implementations. Robust and engaging communication was required, and second, it was important that the ward leaders and facilitators needed to empower and enable frontline staff to make changes. Third, all staff levels required appropriate training. Management and project planning of rolling the programme out, including the sequence in which teams implemented the programme, was important. Leadership, the fifth characteristic, highlighted a need for clear leadership, but also showed how the programme provided opportunity for staff to enhance their leadership skills. Management support and engagement was salient, and this included giving 'permission' to challenge and change existing processes. The seventh main theme was 'Financial and human resource commitment', and in order for the initiative to be sustained, this commitment needed to be long term (White et al., 2013). They also note that the implementation and change literature already emphasises these requirements for effective implementations, which indicates that in many cases, the relevant knowledge has not been transferred to the Productive Ward implementations.

This study forms part of a larger piece of research on an implementation of the Productive Community Services programme that was implemented from July 2010 to March 2012 in a Community Services healthcare organisation in East Anglia, England. The major study employed a mixed methods case study design using participant observation by the first author while working as a Research Analyst as part of the Productive Community Services Implementation Team. It also involved the analysis of qualitative and quantitative data generated during the implementation. The authors examined various aspects of the implementation such as the tensions between the programme theory and practice, the outcomes from the programme and the meaningfulness and reliability of these outcomes. This study focuses on interviews carried out by the first author after the programme concluded during the period April-July 2012, with the aim of exploring staff members' perceptions of the Productive Community Services implementation. Given the positive publication bias in previous literature detailed above (op cit. Wright and McSherry, 2013), the authors focus mainly on themes which highlight aspects of the implementation perceived as most likely to limit the programme's effectiveness. Although some contextual data is presented from the participant observation, examination of the results from the thematic analysis in isolation helps to clearly identify the issue themes from the perspective of the staff members involved.

An Implementation Team was created to implement the programme in over 50 clinical teams ranging from Health Visiting and Physiotherapy to Smoking Cessation and Sexual Health services covering Modules 1-6, and six teams (including District Nursing, Speech and Language Therapy and the Rapid Assessment Unit) implementing Modules 1-9 (see NHS Institute for Innovation and Improvement, 2012a and Fig. 1). The Implementation Team consisted of three staff seconded from within the organisation, two agency staff and the first author, none of whom had experienced implementing change programmes previously. The Productive Community Services Project Manager was seconded from their IT management role from within the organisation and was not a clinician. Three members of the Implementation Team ('Productive Community Services Co-ordinators', two clinical one nonclinical) were allocated a number of teams to work with and worked with relative autonomy. They had no defined mandatory requirements apart from collecting the data required for targets designed by the Commissioners and the Productive Community Services Project Manager, which meant that coverage of the Productive Community Services material that was not directly related to the targets was optional. The targets were developed as part of 


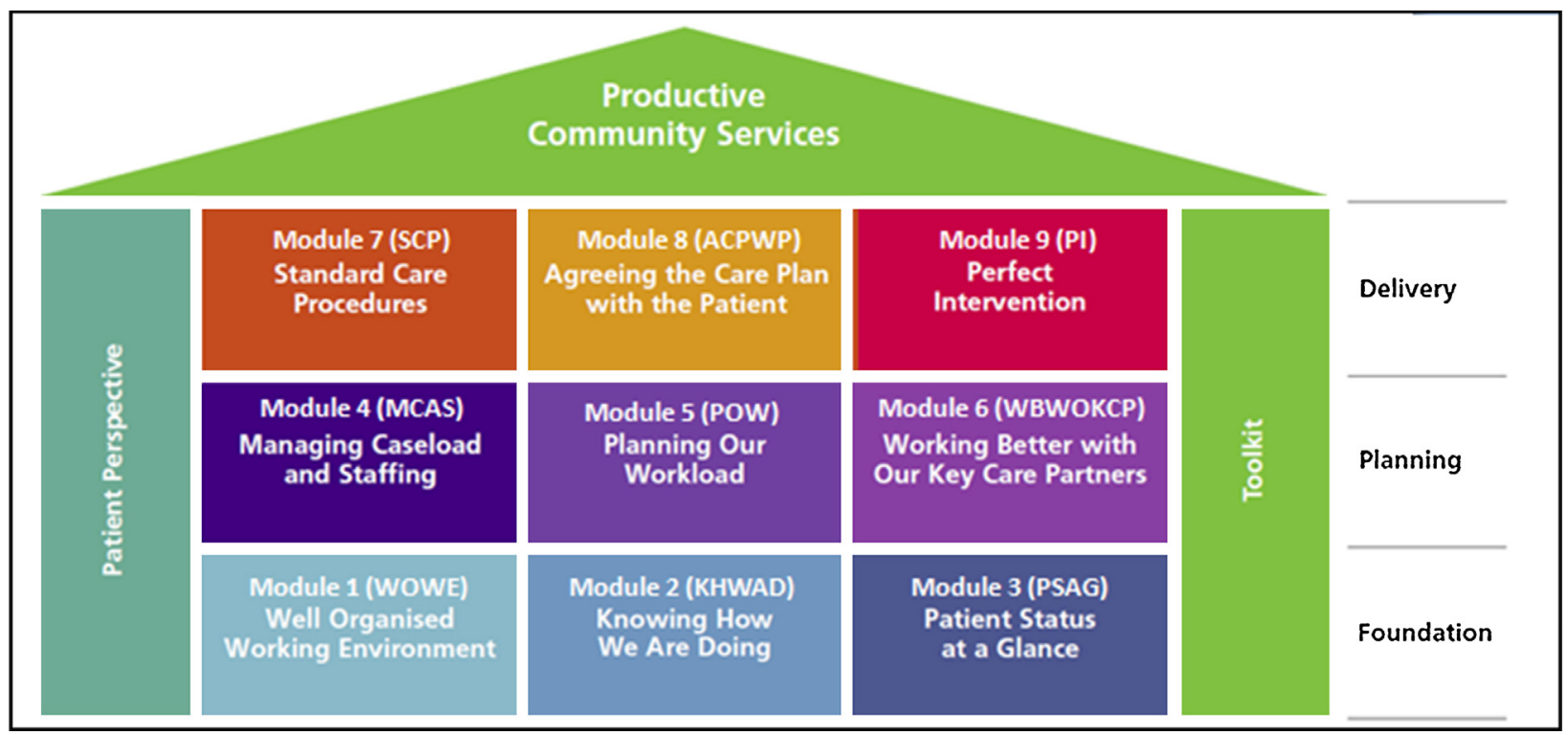

Fig. 1. The Productive Community Services House (NHS Institute for Innovation and Improvement, 2009, p. 5) (module numbers and abbreviations have been added).

the Commissioning for Quality and Innovation framework (CQUIN, see NHS England, 2014), and funding for the implementation was dependent on the targets being achieved. Most of these targets were linked to specific Productive Community Services modules, including, for example, a $10 \%$ reduction in the time taken to find patient information (associated with the 'Patient Status at a Glance' module), and a 10\% reduction in travel mileage claimed (associated with the 'Planning Our Workload' module). The other targets required that patient contact time should increase by $10 \%$ (associated with the whole implementation), and specified the modules that different services should have implemented. Interview data indicated that part of the motivation for implementing Productive Community Services was due to the management team's need to demonstrate to the Strategic Health Authority and Primary Care Trust that they could become an independent organisation, and they felt that implementing this programme would strengthen their case.

\section{Methods}

\subsection{Participants}

61 participants were identified using snowballing and purposive sampling (Ritchie et al., 2003, see Fig. 2) and were invited by email to take part in the study. Eight participants declined, $n=11$ did not respond within the deadline, leaving $n=32$ who were recruited using purposive methods, and $n=10$ using snowballing methods. When commencing interviews with two of the recruited participants, they requested that colleagues from their team join them, forming the opportunistic sample, $n=3$. In total, 40 interviews took place with individual staff, and two group interviews took place; one consisting of two clinical team members and their manager $(n=3)$; and the other consisting of two administrative team members $(n=2)$. The Author had knowingly met $58 \%$ of the participants $(n=26)$ before interview.

In regards to the purposive sampling method, participants were chosen to represent various types of staff groups (see Fig. 3). One member of the SystmOne software support team was also interviewed, as although they had not taken part in the implementation, they had spent a lot of time working with staff who had. Team members were recruited on the basis that as a minimum, they had submitted data for at least one of the Productive Community Services modules (e.g. they had been timed finding patient information for Module 3). However, the team members also included staff who would have been nominated as 'Module Leads' or acted as the main point of contact with the Productive Community Services Coordinators during the implementation $(n=15,54 \%)$. Team members were also split fairly evenly over the main operational directorates where possible (see Fig. 4).

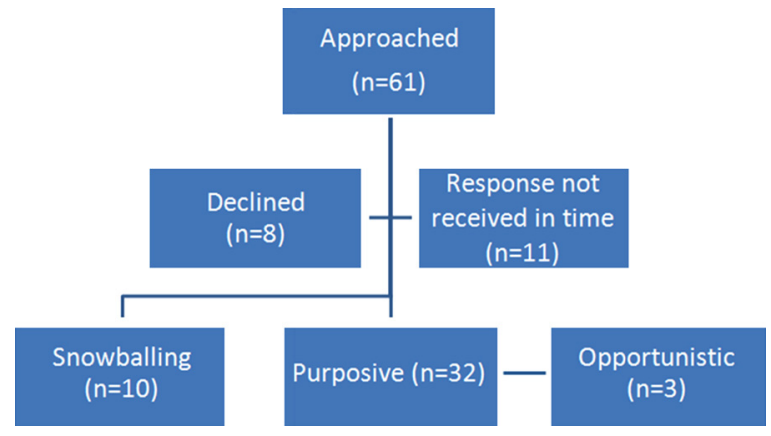

Fig. 2. Breakdown of participant recruitment. 


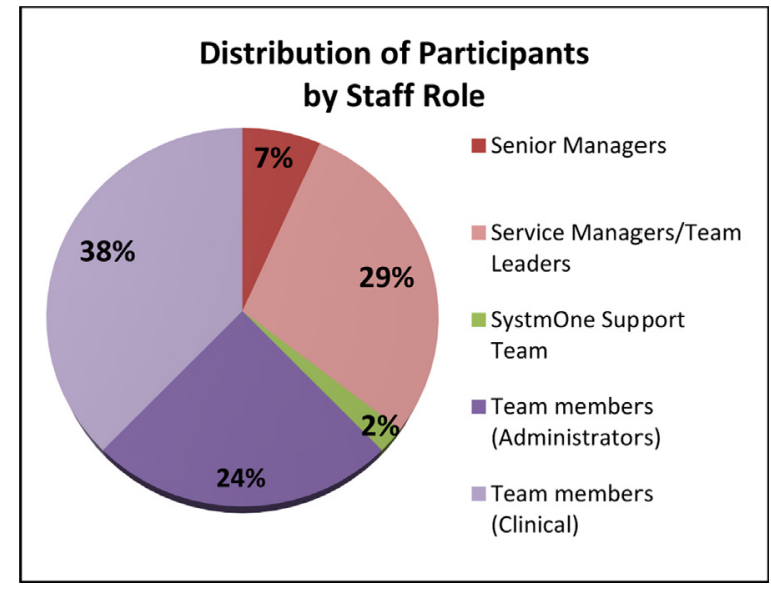

Fig. 3. Distribution of participants by staff role and directorate $(n=45)$.

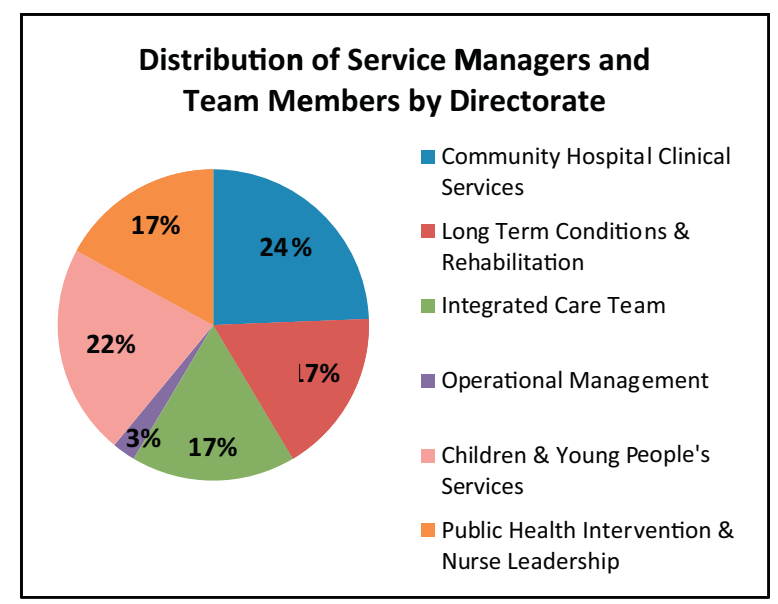

Fig. 4. Distribution of service managers and team members by staff role and directorate $(n=41$; the remaining $n=4$ were not associated with specific directorates).

\subsection{Ethical considerations}

Ethical approval was granted by the University of Essex and the Governance Committee responsible for clinical governance and research within the organisation under study. All participants were sent an email which included information which adhered to guidance from the Ethics
Committee of the British Psychological Society (2009). This included the opportunistic sample who were shown the emailed information at the interview, and sent the email retrospectively. Consent was received by all participants in writing $(n=39)$ or audibly recorded at interview $(n=6)$. Data was stored adhering to the organisation's secure Information Technology policy, and SafeHouse software. Participant data was anonymised using 3-digit codes.

\subsection{Data collection}

The first author carried out the interviews, and a semistructured open-response interview method was used. For the interviews with non-Senior Management, the initial interview questions regarding Productive Community Services were designed to draw out participants' experience of the implementation, and as advocated by King (1994), the interview schedule was slightly modified during the process according to the responses of the participants. Interviews with Senior Management used schedules adapted from the National Nursing Research Unit and NHS Institute for Innovation and Improvement (2010b) during their work into Productive Ward, as these were more appropriate for use with senior managers (see Fig. 5 for examples of the questions used).

Interviews were recorded by dictaphone, and were transcribed by the first author using a simplified version of Jeffersonian method (Potter and Wetherell, 1987) and guidance in Parker (1992) (see Fig. 6). Interviews lasted on average $19 \mathrm{~min}$, ranging from 5 to $45 \mathrm{~min}$.

\subsection{Data analysis}

The first author carried out the coding and analysis, using Braun and Clarke's (2006) guidance to inform the analytical decision-making process. A realist approach was adopted as the experience of the interviewees was sought, and therefore themes were identified at the semantic, or surface level of meaning rather than at a latent, underlying level (Boyatzis, 1998). This analysis aimed to produce a, "Rich description of the dataset," (Braun and Clarke, 2006, p. 83) to emphasise key themes. The software programme NVivo (version 9.2.81) was used. Following Braun and Clarke's (2006) six phases, the first author first familiarised herself with the data, by transcribing the data and then reading and re-reading the dataset. The generation of initial codes (Phase 2) was carried out using the following ideas that arose following the familiarisation process:

\begin{tabular}{|c|c|}
\hline $\begin{array}{l}\text { - Cample interview questions for non-Senior Managers } \\
\text { made as a result of the Productive Community Services } \\
\text { programme in your service? } \\
\text { - As a team you would have been allocated a dedicated } \\
\text { Productive Community Services Co-ordinator. Was this useful? } \\
\text { Would it have been possible to do the Productive Community } \\
\text { Services work without one? } \\
\text { - Do you feel that management (e.g. your line manager or the } \\
\text { management above them) supported Productive Community } \\
\text { Services? } \\
\text { - If there were any changes, do you think these will be sustained } \\
\text { now that the Productive Community Services programme is } \\
\text { over? }\end{array}$ & $\begin{array}{l}\text { Example interview questions for Senior Managers (adapted from } \\
\text { National Nursing Research Unit and NHS Institute for Innovation } \\
\text { and Improvement, 2010b, p. 95) } \\
\text { - Can you just talk about the process of deciding to implement } \\
\text { Productive Community Services in [the organisation]? } \\
\text { - What prompted its implementation? } \\
\text { - Was there any objection to its being run in [the organisation]? } \\
\text { - What is it about The Productive Community Services that } \\
\text { appeals to healthcare organisations? } \\
\text { - Have you had any feedback from staff who have implemented } \\
\text { it? }\end{array}$ \\
\hline
\end{tabular}

Fig. 5. Examples of interview questions. 


\begin{tabular}{|ll|}
\hline$()$. & Pause \\
. & Short pause \\
\hline$\underline{\text { Underlined }}$ & Very short pause \\
(inaudible) & Words uttered with added emphasis \\
{$[$ Area X] } & Round brackets indicate that material in the brackets is either inaudible or there is doubt about its accuracy \\
- & Material in square brackets is clarificatory information, anonymised information, or non-verbal action (e.g. laughter) \\
$?$ & Word sound interrupted (e.g. speaker stops mid-way through word) \\
$\ldots$ & Pitch rises, similar to a question \\
\hline
\end{tabular}

Fig. 6. Transcription conventions used adapted from simplified Jeffersonian method in Potter and Wetherell (1987) and guidance in Parker (1992).

- Experience of Productive Community Services implementation-what Productive Community Services had or had not done.

- What might have affected the Productive Community Services implementation.

- Suggestions as to how the implementation might have been improved.

- Information helping towards a narrative of the Productive Community Services implementation.

Once the data had been coded, the first author grouped the codes into themes and sub-themes (Phase 3), and then reviewed these (Phase 4), checking for any duplication across the thematic map, and testing the themes against the coded data within them. Phase 5 involved refining the defining the theme names and also identifying the overarching narrative themes, before compiling the written report (Phase 6).

\section{Results}

Fig. 7 displays the six overarching narrative themes and 27 associated themes identified from the data set. There were several themes that had aspects that were likely to limit the potential of the programme, however in this report the authors focus on five that they perceived were likely to have the most impact, in addition to the theme of participants' positive perceptions of the implementation. These themes are:

1. Communicating Productive Community Services to Staff.

2. Awareness, knowledge or understanding of Productive Community Services.

3. Sustainability.

4. Relevance.

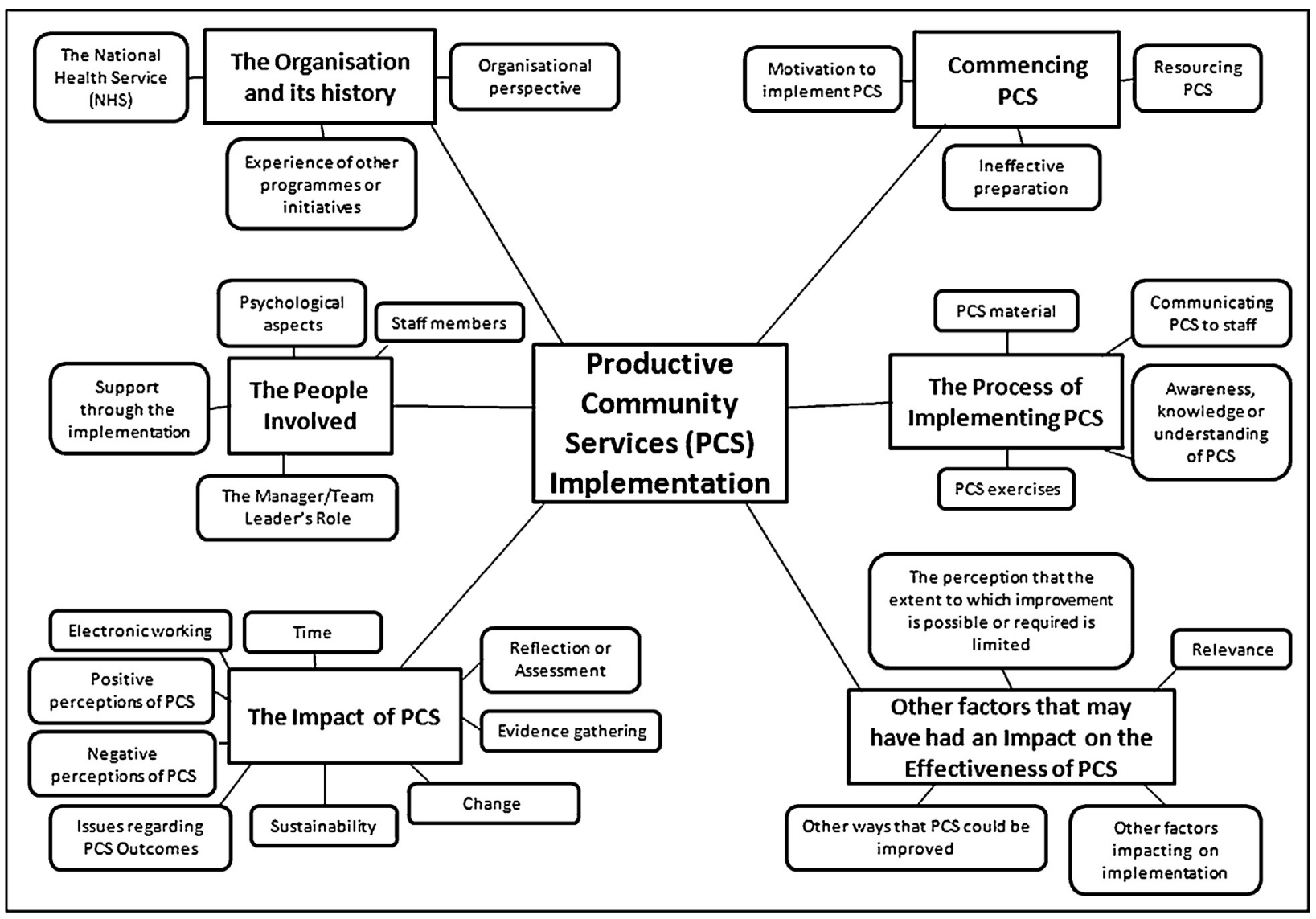

Fig. 7. Overarching narrative themes and themes identified. 
5. Negative perceptions of Productive Community Services. 6. Positive perceptions of Productive Community Services.

\subsection{Communicating Productive Community Services to staff}

Face to face communication from the Implementation Team was perceived to be more effective than via email or by reading the Productive Community Services material. Staff felt that it was important for the Productive Community Services workload to be disseminated down to staff members, however the staff also had a responsibility to retain the information that was communicated:

I think all of them would have heard about it by staff meetings, but I suspect that some will have retained that and some people, it would have just dropped off the radar. (037, Manager)

Staff reported that the way that the programme was communicated, for example via team meeting or email, was not always effective. There was a perception of a lack of communication and little exposure to the programme. Staff had little contact with or knowledge of their Productive Community Services Co-ordinator (their main contact within the Implementation Team), and some staff responses suggested Productive Community Services had been miscommunicated. Staff did not always realise the need to disseminate Productive Community Services to other staff, and also perceived that the significance of Productive Community Services became diluted. One staff member commented,

...it was just something we did a while back and then. . it's gone. . . which is a bit of a shame ... because there's a lot of work involved. . it. . .sort of gets watered down I think as it comes across to us perhaps we water down the importance of it and what we could, what we could gain from it and maybe that's a point that needs to come across if you launch it again. . is actually, what does it mean to the service?... what are they going to get out of it? (033, Team Member (Clinical))

More communication about Productive Community Services was desired (e.g. through organisational communication or workshops), and more needed to be done to introduce Productive Community Services at the beginning of the process, with clearer communication of the outcomes intended.

\subsection{Awareness, knowledge or understanding of Productive Community Services}

Where staff were aware of Productive Community Services, they did not always have an understanding of the whole concept:

045: I think again a lot of us, knew we were doing it but didn't, really understand the whole, concept of Productive Community Services...I think the people that, in the office that co-ordinating it the administrators and, management, understood more, than we did we were kind of, more told to do, to do this and that rather than, maybe why we were doing it
Intvwr: so do you think all the members of your team knew about it?

045: (.) We all knew we were doing something... when I, kind of bandied round the office last week 'Does anyone know anything about productive communities 'cause I've got an interview', I drew blanks from everybody apart from the administrators [laughs] (045, Team Member (Clinical))

Participants often struggled to recall changes made by the programme. Although this could be related to memory (and Kitchell, 1995 warns that memory affects the measurement of innovation), this might also be due to changes not always being attributed to Productive Community Services, the programme's lack of sustainability, or that its impact was so little that it was hard to recall the changes made.

The depth of awareness, knowledge and understanding of Productive Community Services depended on staff members' involvement. This was asserted explicitly, but was also implicit in that participants could talk about what they had been involved with, but little or nothing about the Productive Community Services work they had not been part of:

I think they were all told about whether they all took, they all took it on board, I'm not, certain I think. . .espeespecially for the team, team members that weren't directly involved, it may have just went straight, over their head or, [Productive Community Services] went in one ear and out, out the other. (020, Team Member (Clinical))

\subsection{Relevance}

Staff noted the individual nature of Community Services, where teams are often quite specialist:

...I just think that we're such a (.) massive, diverse organisation. . I can see the thought processes behind a lot of the stuff we do and I think they're good, but. . it's like a one-size fits all. . Whereas, how I work to how, the nurses work to how the [Occupational Therapists] work is all completely different. (028, Team Member (Clinical))

Although some staff felt that Productive Community Services did have some principles that were relevant across service contexts.

You have to (.) think about, do they actually apply to you... Because as I said before it doesn't focus on our service particularly... And there are things but you can work I-you can work round it. (009, Team Member (Clinical))

However a 'Lack of relevancy' was a subtheme clearly identified. Participants noted that more should have been done to examine what was relevant to each team, and the implementation needed to be more bespoke. A pattern emerged where staff felt that Productive Community Services was not relevant to them, but felt it might have been for another service (see Table 1 ). 
Table 1

Evidence demonstrating a perceived lack of relevancy.

\begin{tabular}{|c|c|c|}
\hline Type of staff member & Relevant? & Evidence \\
\hline \multirow[t]{2}{*}{ Relevant to administrators? } & No & Interviewee 015, Administrative Staff \\
\hline & & $\begin{array}{l}\text { "I mean with, the face to face and non-face to face I don't know how relevant } \\
\text { that was to me?... because I'm not, clinical." }\end{array}$ \\
\hline \multirow[t]{2}{*}{ Relevant to a clinician? } & No & Interviewee 002, Clinician in Assessment Rehabilitation Unit \\
\hline & & $\begin{array}{l}\text { So in that respect that module did seem, to be a bit, sort of pointless for us...it } \\
\text { did prove that we look after our patients and they all have the same care...for } \\
\text { their particular condition...but i-it may be it would have been better, i-it } \\
\text { worked better perhaps somewhere like the ward or somewhere like } \\
\text { outpatients." }\end{array}$ \\
\hline \multirow{2}{*}{$\begin{array}{l}\text { Relevant to outpatients, } \\
\text { e.g. podiatry? }\end{array}$} & No & Interviewee 003, Podiatry Manager \\
\hline & & $\begin{array}{l}\text { "For Podiatry, total waste of time... I can't then say for the other AHPs [Allied } \\
\text { Health Professionals]...So for Speech and Language it might have been } \\
\text { helpful for them." }\end{array}$ \\
\hline \multirow{2}{*}{$\begin{array}{l}\text { Relevant to another allied } \\
\text { health professional (AHPs), } \\
\text { e.g. Speech and language therapy }\end{array}$} & No & Interviewee 047B, Speech and Language Therapy Team Member \\
\hline & & $\begin{array}{l}\text { "I think t-the whole package, seemed to be very much directed towards } \\
\text { nursing...teams rather than, AHP teams... and in terms of AHP teams Speech } \\
\text { and Language Therapy (.) are quite different from physio and, and OT I think in } \\
\text { the way that we, we work, so there was quite a bit of it that wasn't (.) necessarily } \\
\text { terribly relevant ... to our service." }\end{array}$ \\
\hline \multirow[t]{2}{*}{ Relevant to nursing? } & No & Interviewee 026, District Nurse \\
\hline & & $\begin{array}{l}\text { “...it never felt there was a...you know, how it was going to, revolutionise our } \\
\text { day to day working ... Just another piece of work to fit in...Possibly how it was } \\
\text { communicated partly... yeah I'm not sure the programme itself was, } \\
\text { relevant... You know?" }\end{array}$ \\
\hline
\end{tabular}

This evidence suggests that in this implementation, Productive Community Services was not always made relevant to users. This may have been due to the Productive Series' origins in the acute sector wards, which is arguably less diverse than Community Services, however according to the NHS Institute for Innovation and Improvement, Productive Community Services was not simply, “...a tweaked version of The Productive Ward" (, p. 15). This lack of relevancy is not just a reflection of the programme, but also of how it was implemented.

\subsection{Sustainability}

Staff acknowledged that old behaviours can often creep back, and that sustaining the changes was hard when faced with other work pressures. Sustaining the improvements made by Productive Community Services was often affected by other changes made in the organisation (for example, site or personnel changes). Some staff felt that changes made during Productive Community Services had been sustained, and that some of the concepts learnt during Productive Community Services had been integrated into the system. For example, the software support team member witnessed staff continuing to use one of the Productive Community Services initiatives which was to display the cost of stock products so that staff were more aware of resources:

... a service turned round and said. ..'Put the cost on there, then'. . .And I was quite impressed. . .I thought, ooh. . . It's filtered through they've got that...so I think, it was a good, good exercise good message (006, Change Agent)

However, others felt that the changes implemented during Productive Community Services were not sustained, and that inefficient practices continued:
Personally I believe old habits die hard and I think people just go back to the way they were ... .and so, although it was supported well by the board and, by especially my line manager at the time (.) I think it's kind of slipped. . .I don't think we're, using everything we learnt from it now, we've started hoarding stuff again and. .. perhaps, reports are made and charts go up, from the reports but they're, out of date they're not kept, up to date. (033, Team Member (Clinical))

Staff also perceived that the pace of the implementation was not sustained. One participant noted of her team leader,

...she would feed back to us at team meetings as to what was happening and when it was happening and...Which modules we would probably be, taking part in. . .But, as I said that was quite a long time ago and it all went very quiet so I wasn't really sure whether we were continuing with it. . . Or if it had stopped. . . I didn't know why that would be... I don't know whether it's fizzled out. . . that's just the impression I got. (027, Team Member (Clinical))

\subsection{Negative perceptions of Productive Community Services}

Some participants were frustrated that the Productive Community Services work had not been efficiently or effectively implemented, and the implementation was seen to be a waste of resources, with little or no benefit. The programme was also seen to take time away from patients and had a negative effect on service and staff:

... for instance timing. .. however many, number of patients on SystmOne we had to time looking at... getting their information up...And then, re-timing it, 
once...all the information was on the front page.. actually it took us longer...when it was on the front page than when w-, we were looking, all over the place 'cause we knew where everything was anyway... So it made no difference...So, you know, I had to pull someone out of clinic to do the timing on them. . . Twice. (003, Manager)

Participants saw Productive Community Services as yet "another" thing to add to the workload, and yet "another" one of these types of programmes. 'Experience of other programmes or initiatives' was another theme identified (see Fig. 7) and the regular implementation of innovations risks creating 'Innovation Fatigue' (Wright and McSherry, 2014), which was indicated in the data. This also highlights the issue of not learning from mistakes made in previous programmes, as this reduces staff members' expectation of future initiatives.

I think it was that it was another, another thing on top of the... workload that's ...happening at the moment, and also there's so much change going on in, [this organisation] and generally...I think it was, oh it was another, another thing, you know burden...so I think, unfortunately, that's. . .(the) latest project that comes in everybody does see those as, as the latest burden.. (030, Team Member (Clinical))

Productive Community Services was also not seen to be embedded or a core part of practice:

...it felt, at the time as though we were being herded...and...rather than being, an integral part of our service and, looking at what we were doing it was definitely a, a bolt-on...maybe if it...had, seemed more relevant and we'd had more time and, and were going to apply it, more in a way that would have been relevant to our service, it would have been very useful to have somebody that we could contact, and say this is what we want to do, how does that fit in with what you need, but, you know so, we didn't make the very best use of [the Coordinator] I suspect. . .but. . .that was partly I think the way the, the thing was, set up. (047, Team Member (Clinical))

\subsection{Positive Perceptions of Productive Community Services}

Participants generally felt that the concept behind Productive Community Services was good, and it empowered staff. Staff reported the programme had increased awareness of their services, for example, in relation to performance, to poor or inefficient working practices, of stock and time resources. The participant quoted in the extract below described how her team engaged with the Module 2 work on service statistics:

. .it's been quite interesting because, for instance all the stats and stuff, people are looking at them and going 'ooh ooh' lots of 'ums' and 'aars' and...sort of 'oh that looks right' or 'oh that's good' or 'that- you know maybe we can do something about that.' (001, Team Member (Clinical))
Staff experienced many benefits, such as the improvement of stock control, working environment and time management, the saving of time during processes, better use of their Electronic Patient Records system, and a reduction in paper used. Processes were improved, and improvements made during the implementation sparked further improvement.

It's probably changed how I feel, because I was quite involved in it. .Just in erm (.) finding a more efficient way, of doing things. . .I tend to have a lot of my work around me [laughs] and it has sort of made me (.)streamline ...what I do...so it has worked for me... and in some regards it has worked for the others but they're just not aware that it's [Productive Community Services] that's, made that change. (033, Team Member (Clinical))

\section{Discussion}

The objective of this study was to explore organisational staff members' perceptions of a Productive Community Services implementation. In addition to the theme of the positive perceptions of the programme, this report focuses on five of the themes identified which highlight parts of the implementation that were likely to limit its potential. In comparing these results with previous findings, other implementations of Productive Series programmes have been reported to generate various improvements (e.g. Dean, 2014; Lennard, 2014; Lipley, 2009), and similarly in this implementation, staff reported benefits such as improved stock control, time management, and use of Electronic Patient Records. Although the existing literature focuses less on the challenging aspects of the programme, in a national web-survey of frontline staff ( $n=150)$, National Nursing Research Unit and NHS Institute for Innovation and Improvement (2010b) identified some of the barriers to implementation which had similarities with the issues identified in this study. These included the facilitators' lack of understanding of specific ward contexts ( similar to issues found within the theme of Relevance, where the implementation appeared not to have been made relevant to different service contexts) and the difficulty of sustaining improvements (found in the theme of Sustainability). In addition, although op cit. Davis and Adams' (2012) smaller sampled study on staff perspectives also identified some negative aspects of the implementation (e.g. 'Anxiety and defensiveness' and 'Challenges'),the analysis in this study offers a more detailed narrative of the implementation which highlights specific areas of difficulty that future practitioners of the programme should be aware of.

For example, White et al. (2013) proposes that engaging communication is crucial to implementation, and the data indicated that this requirement was not always met. This may be explained by the inexperience of the implementation team, as although they had good knowledge of the organisation, they had little experience of implementing change. The change and innovation literature emphasises the salience of communication (for example see Lewis et al., 2006), however this knowledge did not reach the 
team, or they were not able to effectively put it into practice. As this replicates findings by White et al. (2013) for the Productive Ward implementations, this reinforces the need to find ways to better bridge the gap between theory and practice for implementation teams.

There are clear links between the first two themes described, as awareness, knowledge or understanding of an innovation can only be achieved by effective communication. Face to face contact was seen as more effective than email contact, and this is important to consider in a Community Services organisation where communication can be difficult across multiple sites (working across multiple sites was also identified as a barrier to Productive Ward implementation by National Nursing Research Unit and NHS Institute for Innovation and Improvement, 2010b). For example, although communication by telephone or email is relatively inexpensive, it may be a better use of resources to travel to staff in person if they are more likely to engage with the programme as a result.

Staff also suggested that communication via workshops or organisational channels (e.g. the intranet) might have improved the process. However, although awareness can be increased using these methods (Leeman et al., 2007) implementation or adoption of the innovation is still not guaranteed (Grimshaw et al., 2004, cited in Leeman et al., 2007). Further research is required to explore the most effective way of communicating the innovation or change message, particularly in Community Service settings where many staff are lone workers or based over multiple sites.

The services in Community Services organisations are also specialist and diverse, so innovations need to be already relevant, or adapted easily to be made relevant to potential adopters. However, the analysis found staff perceived the programme to have little relevance to their work. The participant observation of the implementation that was carried out identified other factors that were likely to contribute towards this lack of relevancy. For example, the Productive Community Services material appears quite prescriptive, emphasising Community Nursing models of care rather than clinic-based services. The Implementation Team (mostly seconded from posts within the organisation) were inexperienced in programme implementation and had tight deadlines imposed by the Commissioners, and so struggled to adapt the material to be relevant to all services within the time available. Further research is required to explore this issue of relevancy in other organisations implementing Productive Community Services, and also to look at how knowledge transfer (Berta et al., 2005) can be improved for internally resourced implementation teams, particularly as this option is likely to be utilised more regularly in financially challenged healthcare organisations.

Some other significant contextual factors may also have contributed towards the issues identified in these themes. These include the motivation of the organisation's management team to implement the programme (to strengthen their case to become a standalone organisation, which meant that being seen to implement the programme may have been more important than the outcome), that the majority of services only implemented six out of nine modules, and also the way that the programme was commissioned. 'Local ownership and real empowerment' was one of the organisational factors identified as influencing the success of the Productive Ward programme (National Nursing Research Unit and NHS Institute for Innovation and Improvement, 2010b), and imposing generic commissioned targets took this local ownership away from frontline staff. In addition, during the participant observation, the first author observed that there was a strong emphasis on implementing the work that was required for the Commissioners' targets, which meant that Productive Community Services material surplus to these requirements was not always covered. As organisations increasingly rely on commissioning for innovation, this highlights an area for further research.

White et al. (2013) identified a bias in the literature towards the publication of positive results, but the publication of more negative results arguably highlights more clearly the need for further research to be carried out. However, despite the negative issues highlighted, other benefits were identified during the implementation which included the reduction of excess stock, improved referral procedures and reduced time in finding patient information. It should also be acknowledged that although the programme aims to release time, improving quality may inconvenience or have a negative consequences for staff members. Ideally there should be a balance between the impact on staff and other parties, however this is not always possible. Therefore it may be inevitable that staff will have negative perceptions of an improvement initiative, particularly if they cannot see how the changes benefit the patient. As nurses are motivated by being able to care for and help patients (Newton et al., 2009), the programme should be communicated so that the relationship between the change implemented and the benefit to patients is clear.

\subsection{Limitations}

The first author who led the interviews, had been part of the implementation team and had met the majority of participants in that capacity, so demand characteristics may have been displayed. The first author also analysed the data alone, so inter-rater reliability could not be measured. A 'critical friend' (McGrath and O'Toole, 2012) was employed to read the final report, however the interviewer's role in the construction of knowledge (Rapley, 2001) should be recognised. Rather than creating a positivistic 'bias', the first author's experience of the implementation was an essential part of theory development.

Caution should also be taken when generalising the results of this analysis to other organisations, as the data are based on the way that Productive Community Services was adapted in the organisation under study. Focus here has also been on perceptions of the implementation rather than the staff members themselves who also factored in the implementation's effectiveness. In addition, although the participants were not all heavily involved in the programme, there was a sampling bias as the criteria for Team Members ensured that they had submitted data for 
at least one Productive Community Services module, so team members who were not involved in this way were not represented. However, as those that took part often knew little about the programme, this suggests that those with no involvement will have had even less knowledge. This bias then highlighted the salience of effective communication and staff involvement even more. This study also forms part of a larger piece of research, and although some of the significant contextual factors identified in the major study have been discussed, the detail focused on here forms only part of the broader picture. Further findings from the major study will be submitted for publication in due course.

\section{Conclusion}

Much of the previous research on Productive Series programmes has recruited participants heavily involved in the implementation, and with a positive bias. Although positive benefits of the Productive Community Services implementation were reported in this study, focus on five of the themes identified suggests that many aspects of the implementation could have been improved. There was a lack of understanding or knowledge of the programme, ineffective communication, and a perceived lack of relevance of the programme. This indicated that there was a knowledge transfer gap, as implementation theory did not appear to have always been used in practice. The Productive Series programmes are designed to be led by frontline staff, however the issues identified suggest that this was not always achieved effectively. If healthcare organisations implement programmes using internal resources rather than employing experienced external consultants, they need to be wary of false economy, and look for ways to ensure that implementation knowledge is transferred to the organisation. The designers of programmes for Community Services in healthcare such as Productive Community Services also need to ensure that they are made relevant or easily adaptable to the various specialisms that exist in Community care. The process of commissioning innovations like Productive Community Services and the experience of implementation teams are also likely to have an impact on the effectiveness of the implementation. Publication of implementations focusing on less favourable results may promote the need for further research to improve these areas.

\section{Conflict of interest}

During the study the first author was carrying out research on the programme as a member of the implementation team, and is now working within the organisation under study.

\section{Funding}

This study was funded by the organisation under study.

\section{Ethical approval}

Ethical approval was granted by the University of Essex and the organisation's Governance Committee.

\section{References}

Avis, K., 2012. CASIL Report-Releasing Time to Care Productive Ward \& Productive Mental Health Ward Last Retrieved, 2 March 2014, from 〈http://www.hqc.sk.ca/Portals/0/documents/casil-report-january2012.pdf $\rangle$

Berta, W., Teare, G.F., Gilbart, E., Ginsburg, L.S., Lemieux-Charles, L., Davis, D., Rappolt, S., 2005. The contingencies of organizational learning in long-term care: factors that affect innovation adoption. Health Care Manage. Rev. 30 (4), 282-292.

Bevan, H., 2010. How can we build skills to transform the healthcare system? J. Res. Nurs. 15 (2), 139-148.

Blakemore, S., 2009. How productive wards can improve patient care. Nurs. Manage. 16 (5), 14

Boyatzis, R.E., 1998. Transforming Qualitative Information: Thematic Analysis and Code Development. Sage Publications, Thousand Oaks, London, New Delhi.

Braun, V., Clarke, V., 2006. Using thematic analysis in psychology. Qualitat. Res. Psychol. 3 (2), 77-101.

Callard, L., 2008. Working with nurses in the community. Nurs. Times 105 (9), s15.

Davis, J., Adams, J., 2012. The 'Releasing Time to Care - the Productive Ward' programme: participants' perspectives. J. Nurs. Manage. 20, 354-360.

Dean, E., 2014. Creating more time in the day for patient care. Nursing Management 21 (1), 9.

Ethics Committee of the British Psychological Society, 2009. Code of Ethics and Conduct: Guidance published by the Ethics Committee of the British Psychological Society. The British Psychological Society, Leicester.

Foster, S., Gordon, P., McSherry, W., 2009. Rolling out Productive Ward foundation modules across a hospital trust. Nurs. Times 105 (30), 28-30.

Harrison, S., 2008. Accident and infection charts put on display to motivate ward team. Nurs. Stand. 22 (25), 9.

King, N., 1994. The qualitative research interview. In: Symon, G.E., Cassell, C.E. (Eds.), Qualitative Methods in Organizational Research: A Practical Guide. Sage Publications, London, Thousand Oaks, New Delhi, pp. 14-36.

Kitchell, S., 1995. Corporate culture, environmental adaptation, and innovation adoption: a qualitative/quantitative approach. J. Acad. Mark. Sci. 23 (3), 195-205.

Leeman, J., Baernholdt, M., Sandelowski, M., 2007. Developing a theorybased taxonomy of methods for implementing change in practice. J. Adv. Nurs. 58 (2), 191-200.

Lennard, C., 2014. Productive Ward initiative promotes better communication between mental health teams and ensures timely discharge for patients. J. Psychiatr. Ment. Health Nurs. 21 (1), 93-96.

Lewis, L.K., Schmisseur, A.M., Stephens, K.K., Weir, K.E., 2006. Advice on communicating during organizational change. J. Bus. Commun. 43 (2), $113-137$.

Lipley, N., 2009. Productive wards hailed for transforming care. Nurs. Manage. 16 (4), 4

Manning, S., 2011. Working toward improving quality and efficiency in school nursing. Br. J. Sch. Nurs. 6 (8), 373-374.

McGrath, H., O'Toole, T., 2012. Critical issues in research design in action research in an SME development context. Eur. J. Train. Dev. 36 (5), 508-526, http://dx.doi.org/10.1108/03090591211232075.

Moore, D., Blick, G., Leggott, J., Bloodworth, K., 2013. Assessment of the implementation of the Productive Ward and Productive Operating Theatre programmes in New Zealand. Health Quality \& Safety Commission and the Ministry of Health, New Zealand.

National Nursing Research Unit and NHS Institute for Innovation and Improvement, 2010a. Improving Healthcare Quality at Scale and Pace-Lessons from The Productive Ward: Releasing Time to Care ${ }^{\mathrm{TM}}$ Programme. NHS Institute for Innovation and Improvement, Warwick.

National Nursing Research Unit and NHS Institute for Innovation and Improvement, 2010b. The Productive Ward: Releasing Time to Car$\mathrm{e}^{\mathrm{TM}}$, Learning and Impact Review. NHS Institute for Innovation and Improvement, Warwick, pp. 1-108.

Newton, J.M., Kelly, C.M., Kremser, A.K., Jolly, B., Billett, S., 2009. The motivations to nurse: an exploration of factors amongst undergraduate students, registered nurses and nurse managers. J. Nurs. Manage. 17 (3), 392-400.

NHS East of England, 2010. Releasing Time to Care: The Productive Ward Report on the Impact and Sustainability of the Programme across Trusts in the East of England NHS. NHS East of England, , pp. 1-58 (Unpublished).

NHS England, 2014. Commissioning for Quality and Innovation (CQUIN): 2014/15 Guidance Retrieved from 〈http://www.england.nhs.uk/wpcontent/uploads/2014/02/sc-cquin-guid.pdf 
NHS Institute for Innovation and Improvement, 2009. Productive Community Services: Releasing Time to Care-Toolkit, Version 1. NHS Institute for Innovation and Improvement, Coventry.

NHS Institute for Innovation and Improvement, 2011. The Productive Series, , Last Retrieved, 20 March 2011, from 〈http://www.institute.nhs.uk/quality_and_value/productivity_series/ the_productive_series.html $\rangle$

NHS Institute for Innovation and Improvement, 2012a. Productive Community Services-About the Programme Last Retrieved, 8 October 2012, from NHS Institute for Innovation and Improvement Website: 〈http://www.institute.nhs.uk/quality_and_value/\%20productivity_series/productive_community_services.html $>$

NHS Institute for Innovation and Improvement, 2012b. The Productive Series (An Introduction), , Last Retrieved, 19 March 2012, from 〈http:// www.institute.nhs.uk/quality_and_value/productivity_series/ the productive series.html)

NHS Institute for Innovation and Improvement, 2014. About the NHS Institute for Innovation and Improvement Last Retrieved, 19 November 2014 from 〈http://www.institute.nhs.uk/organisation/about nhsi/about_the_nhs_institute.html $\rangle$

NHS Scotland, 2008. Releasing Time to Care Evaluation: Healthier Scotland. Scottish Government.

NHS Scotland, 2013. Releasing Time to Care: Making our Priorities Possible-Final Report Last Retrieved, 19 April 2014, from 〈http:/ www.healthcareimprovementscotland.org/our_work/person-centred_ care/releasing_time_to_care/rtc_final_report.aspx $\rangle$

Parker, I., 1992. Discourse Dynamics: Critical Analysis for Social and Individual Psychology. Routledge, London, New York.

Potter, J., Wetherell, M., 1987. Discourse and Social Psychology: Beyond Attitudes and Behaviour. Sage Publications Ltd, London, Newbury Park, Beverly Hills, New Delhi.
Rapley, T.J., 2001. The art(fulness) of open-ended interviewing: some considerations on analysing interviews. Qualitat. Res. 1 (3), 303-323.

Ritchie, J., Lewis, J., Elam, G., 2003. Designing and selecting samples. In: Ritchie, J., Lewis, J. (Eds.), Qualitative Research Practice: A Guide for Social Science Students and Researchers. Sage Publications, London, Thousand Oaks, New Delhi, pp. 77-108.

Smith, J., Rudd, C., 2010. Implementing the productive ward management programme. Nurs. Stand. 24 (31), 45-48.

White, M., Waldron, M., 2014. Effects and impacts of productive ward from a nursing perspective. Br. J. Nurs. 23 (8), 419-426.

White, M., Wells, J.S., Butterworth, T., 2014. The transition of a large-scale quality improvement initiative: a bibliometric analysis of the productive ward: releasing time to care programme. J. Clin. Nurs. 23 (17-18), 2414-2423, http://dx.doi.org/10.1111/jocn.12585.

White, M., Wells, J.S.G., Butterworth, T., 2013. The productive ward: releasing time to Care ${ }^{\mathrm{TM}}$ - what we can learn from the literature for implementation. J. Nurs. Manage. 22 (7), 914-923, http:// dx.doi.org/10.1111/jonm.12069.

Wilson, G., 2009. Implementation of releasing time to care-the productive ward. J. Nurs. Manage. 17 (5), 647-654.

Wright, S., Cleaver, C., Dibblin, A., 2012. Implementing productive community services modules. Br. J. Sch. Nurs. 7 (1), 37-41.

Wright, S., McSherry, W., 2013. A systematic literature review of releasing time to care: the productive ward. J. Clin. Nurs. 22 (9-10), 1361-1371.

Wright, S., McSherry, W., 2014. Evaluating the productive ward at an acute NHS trust: experiences and implications of releasing time to care. J. Clin. Nurs. 23 (13-14), 1866-1876, http://dx.doi.org/10.1111/ jocn. 12435.

York Health Economics Consortium and NHS Institute for Innovation and Improvement, 2010. Service Modelling of the Productive Community Services Programme Report. The University of York, York, pp. 1-18. 